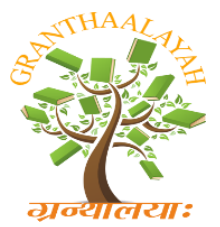

\author{
INTERNATIONAL JOURNAL OF RESEARCH - \\ GRANTHAALAYAH \\ A knowledge Repository
}

\title{
ASSESSMENT ON SUITABILITY OF NORMALIZING AND PROBABILITY TYPE BENTHIC INDICES FOR PREDICTION OF BEHAVIOR OF INLAND WATER BODY
}

\author{
Gayatri Gautam
}

\begin{abstract}
Natural variability in diversity of benthic macro invertebrate fauna or benthos has become a valuable tool in assessing, modeling and monitoring of water quality of inland water body with respect to its portability and of pollution level. However, inappropriate use of these indices may leads to false interpretation or prediction of behavior of inland water body. In this study we have employed two normalizing (i.e Shannon-Wiener Index (H'), Pielou's Evenness (J')) and one probability type (HurlbertPIE Index (PIE)) indices to evaluate behavior of Baikona tank water body between Jan-2008 to Dec 2009. Sampling was carried out for period of 24 months at three different location and diversity of benthos for each location was tabulated.

It is observed that monthly variation these indices show same trend during observation period. Coefficient of correlation among normalizing indices is observed lesser degree when compared to correlation between normalizing and probability type index. Degree of correlation is equitable when samples in all three sampling stations are mapped as single for each sampling period. It can be summarized that to model the tank behavior (i)both normalizing type and probabilistic type indices to be considered.(ii)all samples taken at a time at different locations are to be mapped as single sample.
\end{abstract}

Keywords:

Shannon-Wiener Index (H'), Hurlbert PIE Index (PIE), Pielou's Evenness (J'), variation, correlation coefficient.

\section{INTRODUCTION}

Environmental pollution becomes primary concern worldwide due to increasingly deteriorating environmental condition. Air and water are the two predominant natural resources which are impacted the most by various human activities. Mixing of industrial effluent and sewage in to natural water reservoir resulted in to significant reduction in availability of drinking water. In spite of stringent discharge regulation increasing numbers of water bodies are getting polluted. Consequently, it's become paramount important to continuously monitor the quality of water and also derived the predictive model indicating pollution level in water body. Biological indicator (bio indicator) is emerging as ideal tool to monitor water quality due to their higher sensitivity, specificity and easy monitoring. Benthos is group of organisms which found in fresh water bodies and known to be highly sensitive to environmental changes. Due to this characteristic assessment of benthos diversity with time, gives a faire indication of water bodies getting polluted or not. Diversity or community structure of benthos can be quantify using various population level indices 
like Shannon-Wiener Index (H') and Pielou's Evenness (J') as assessment of normalized diversity and more dependent on sample size while Hurlbert Index (SHPIE) can be used as probabilistic indices and less dependent on sample size. However, each quality indices were developed based on certain assumption and therefore there is always a possibility of getting different results for each indices. Consequently, one should employed more than one indices to assess or predict the quality of inland water body.

Here in this study three biotic indices are studied on Baikona tank of Satna dist. MP in order to (i) Analyze monthly term variability of indices, (ii) to compare and correlate outcome of each indices in terms of predictive behavior of water body. The three diversity indices chosen for correlation study are : the Shannon-Wiener Index $\left(\mathrm{H}^{\prime}\right)$, the and Pielou' $\mathrm{s}$ Evenness(J' ),Hurlbert Index(SHPIE). These three were chosen because first two are normalizing indices whereas last one is probability index. The Shannon-Wiener Index $\left(\mathrm{H}^{\prime}\right)$ is the most commonly used diversity index in benthic ecology, which incorporates species richness as well as equitability. Pielou's Evenness (J) reflects the even occurrence of species within a community. Both indices, Shannon- Wiener and Pielou's Evenness, depend on the sample size. In contrast, the SH Hurlbert PIE represents the probability of interaction between species.

\section{MATERIAL AND METHODS STUDY SITE}

The study was carried out at Baikona tank which is fresh water rervoire situated near Rampur baghelan town and is largest tank of district. The tank covers an area of 17 hectares in rainy season which gradually decreases upto 8.5 hectares during summer season. The average depth of this tank is about 25 feet in rainy season which gradually decreases upto 12 feet in summer season. The tank is major source of water for nearby villages and also affected by nearby cement industries.

\section{SAMPLING}

Present investigation was carried out during January 2008 to December 2009. For the collection of macro benthic fauna Ekman dredge $(523 \mathrm{sq} . \mathrm{cm})$ was used. Sediment samples so collected were passed through mesh sieve of $0.5 \mathrm{~mm}$ to separate animals and thereafter preserved in $5 \%$ neutralized formalin. Organisms were identified up to the species.

Three sampling stations were selected for studies which were designated as A, B and C.

Station-A: Mostly disturbed area with respect to water movement, near the north-west side of the tank.

Station-B: Semi-disturbed area of the south-east part of the tank where human and animal activities are found.

Station-C: Central undisturbed part of the tank. 


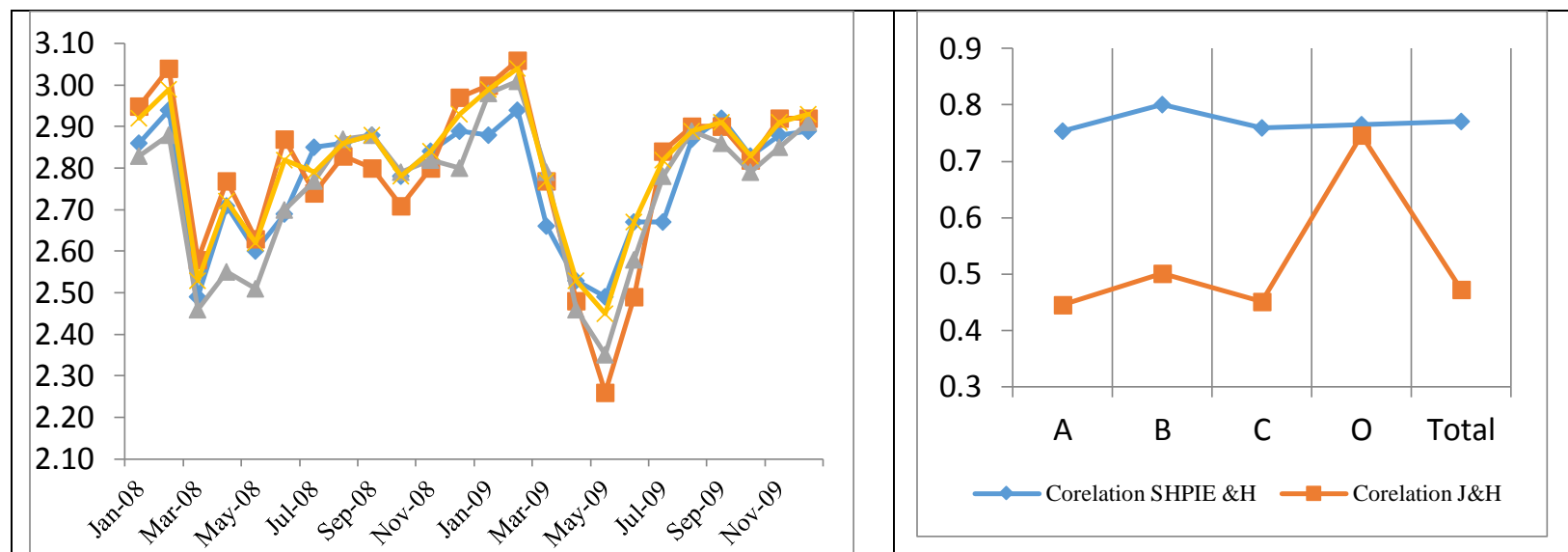

Fig1.Monthly variation of Shannon Index $\left(\mathrm{H}^{\prime}\right)$ for stn. ABC \&O

Fig4Comparison of coefficient of correlation
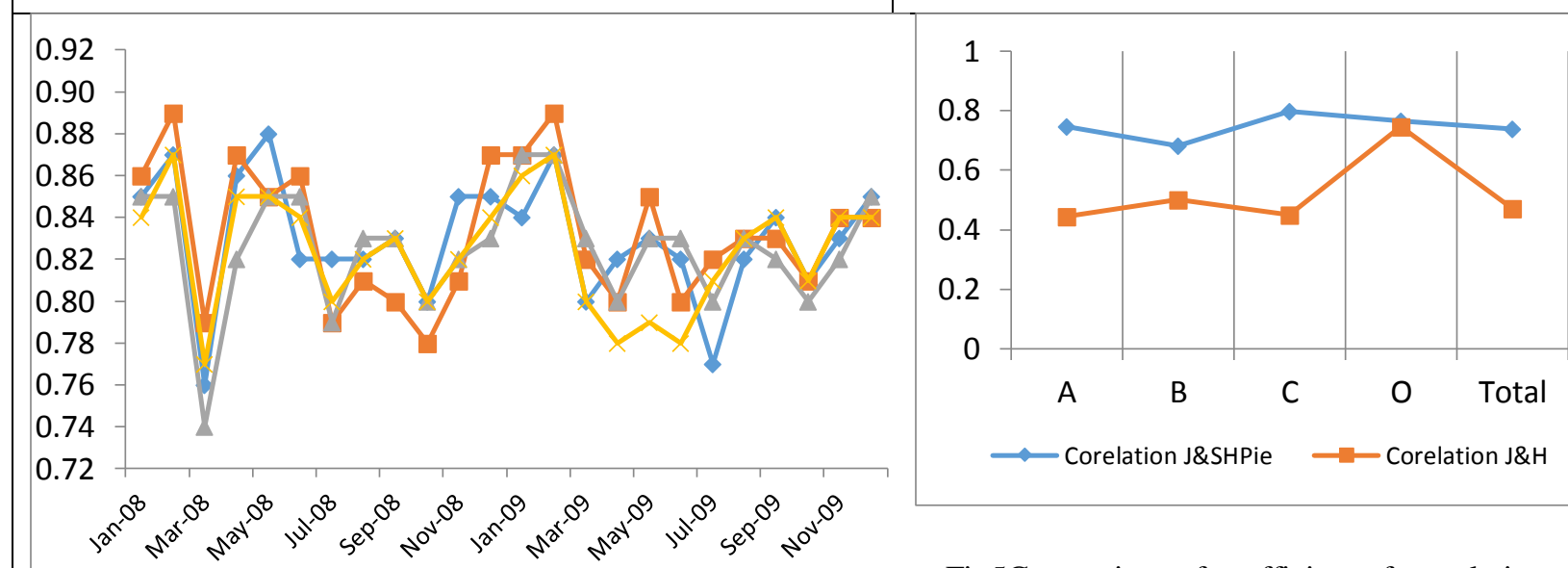

Fig5Comparison of coefficient of correlation

Fig2.Monthly variation of Paleu evennes J'
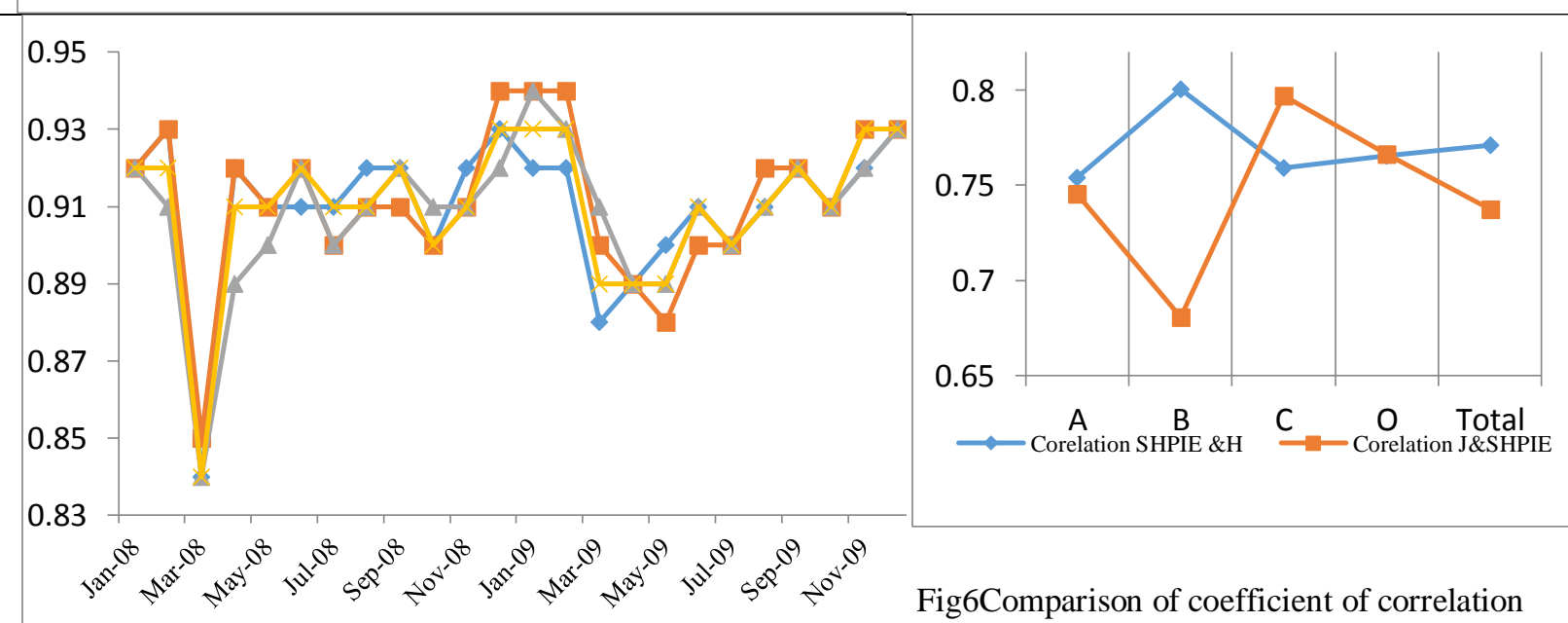

Fig6Comparison of coefficient of correlation

Fig.3. Monthly variation of SH PIE 


\section{INDICES}

Shannon Index [H' (H Prime)]: The formula to calculate Shannon index is as:

$$
H^{\prime}=-\sum_{i=1}^{S} p_{i} \ln p_{i} \text { Where, } \mathrm{H}^{\prime}=\text { species diversity. } n_{i}=\text { the number of }
$$

individuals in species, i; the abundance of species i. $S=$ the number of species (species richness). $N=$ the total number of all individuals in samples i.e. summation of $n_{i .} . p_{i}=$ the relative abundance of each species, calculated as the proportion of individuals of a given species to the total number of individuals in the community: $\mathrm{n}_{\mathrm{i}} / \mathrm{N}$.

It is the information entropy of distribution, treating species as symbols and their relative population size as entropy. Large H'indicates greater diversity.

\section{Evenness:}

$\left[\mathrm{J}^{\prime}(\mathrm{J}\right.$ prime $\left.)=\mathrm{H}^{\prime} / \mathrm{H}_{\text {max }}^{\prime},\right]$ : where $\mathrm{H}^{\prime}$ is the Shannon index as defined above, $\mathrm{H}^{\prime}{ }_{\max }=\ln S,(\log$ natural of $\mathrm{S}$ ) $\mathrm{H}^{\prime}$ max , is the maximum value of $\mathrm{H}^{\prime}$ and $\mathrm{S}$ is the species richness. Evenness depends on the relative abundance of individuals representing each taxa.

It tells how evenly the proportions of taxa are distributed in a sample.it seperates the effect of different population sizes.

Hurlbert's PIE (probability of interspecific encounters) (Hurlbert, 1971):

$$
P I E=\left(\frac{N}{N-1}\right) \cdot\left(1-\sum_{i=1}^{s} p i^{2}\right)_{\text {Where symbol denominations are same as above. }}
$$

PIE means that if an individual enters a community and encounters two individuals at random, they will belong to different species. In high PIE communities, there would be less reliance by species on random process in searching behavior.

A correlation coefficient is a statistical measure of the degree to which changes to the value of one variable predict change to the value of another. In positively correlated variables, the value increases or decreases in tandem. In negatively correlated variables, the value of one increases as the value of the other decreases.

\section{DATA ANALYSIS}

The results for species number and abundance from the stations $\mathrm{A}, \mathrm{B}$ and $\mathrm{C}$ were pooled and treated as replicates for the area. All three samples of each sampling period are replicated as single sample from tank and mapped as overall values $(\mathrm{O})$ for representation of full tank area the indices were calculated through formulae.

All the values A, B, C and O (overall) of calculated indices are plotted for each month (Fig1, 2 and 3). Also correlation coefficient values obtained among them are plotted for all three combinations. (Fig4, 5 and 6). 


\section{RESULTS}

The monthly variation of all three indices follow nearly same trend. Coefficient of correlation of PIE (probability index) with J' and H' is observed higher when compared with correlation between $\mathrm{J}$ and $\mathrm{H}$ (normalizing indices). Correlation degrees are fairly equal for overall $(\mathrm{O})$ values. It shows that (i) to model the effects of any disturbances in tank (inland water body) all samples from different locations are to be combined and mapped as one sample. (ii) Both types of indices are to be used for modeling tank behavior through macro invertebrate community indices.

\section{REFERENCES}

1. Gayatri gautam, "Studies on community composition,population dynamics and species diversity of macroinvertebrate fauna of Baikona tank of dist. Satna(MP) ",PhD Thesis.

2. Ingrid Kröncke,Henning Reiss "Influence of macrofauna long-term natural variability on benthic indices used in ecological quality assessment” Marine Pollution Bulletin 60 (2010) 5868.

3. Ste phanie Gasco 'n*, Sandra Brucet, Jordi Sala, Dani Boix, Xavier D. Quintana

" Comparison of the effects of hydrological disturbance events on benthos and plankton salt marsh communities” Estuarine, Coastal and Shelf Science 74 (2007),419-428.

4.www.wikipedia.com.

5.Asha sinha 1995, Studies on factors controlling occurrence and distribution of benthic macrofauna in flowing water ph.d. thesis ranchi UTD.

6. Boyle, T.Smillie, G. Anderson, J. and Beeson, D., 1990. A sensitivity analysis of nine diversity and seven similarity indices Res J WPCF 62, pp. 749-762. 